\title{
Mesodiverticular Band Leading to Intestinal Obstruction: A Case Report
}

\author{
Dr. Vivek Bhasker ${ }^{1}$, Dr. Brajesh Kumar ${ }^{2}$, Dr. R. S. Sharma ${ }^{3}$ \\ ${ }^{1}$ Senior resident, General Surgery, RIMS, Ranchi, Jharkhand, India \\ ${ }^{2}$ JRA-II, General Surgery, RIMS, Ranchi, Jharkhand, India \\ ${ }^{3}$ Associate Professor, General Surgery, RIMS, Ranchi
}

\begin{abstract}
Meckel's diverticulum is seen in approximately 2\% of the population. Meckels diverticulum leading to intestinal obstruction is a rare complication in such cases. In this case report we describe one such case of meckels diverticulum which formed a mesodiverticular band and ultimately presented as intestinal obstruction.
\end{abstract}

Keywords: meckel's diverticulum, mesodiverticular band, exploratory laparotomy, intestinal obstruction

\section{Introduction}

Meckel's diverticulum is the most common congenital abnormality of the gastrointestinal tract affecting around 2\% of population ${ }^{1 .}$ It is a true diverticulum containing all layers of the intestinal wall ${ }^{5}$. Johann Meckel, who first described this condition in 1812, stated that the risk of associated complications was about $25 \%$ but in study done by Joseph J. Cullen, cumulative risk of developing complications over lifetime was $6.4 \%$ and more complicated cases were seen in the younger age group ${ }^{8}$. Complications of Meckel's diverticulum include hemorrhage, intestinal obstruction, diverticulitis, umbilical discharge, perforation and peritonitis ${ }^{3}$. Meckel's diverticulum is an uncommon cause of intestinal obstruction in adult life ${ }^{5 ; 6}$. Rarely Meckel's diverticulum is complicated by a mesodiverticular band, which is believed to be a remnant of a vitelline artery. When this abnormality causes intestinal obstruction it is associated with high mortality ${ }^{5}$.

Here we are reporting one such rare case of mesodiverticulr band leading to intestinal obstruction.

\section{Case Report}

A 12 yrs old male patient, Anup Toppo, presented in surgical emergency of Rajendra Institute of Medical Sciences, Ranchi, Jharkhand ; with gradually progressive abdominal distension (for 4 days) and pain abdomen (for 1 day). He had not passed stool for 4 days. On examination patient was conscious alert and cooperative. Pulse rate was 120/min; BP- 100/70mm Hg. Abdomen was distended and mildly tender. Rectum was empty on per rectal examination. Clinical diagnosis of intestinal obstruction was made. Routine blood examination showed raised TLC count. Blood electrolytes were within normal limits. X-ray abdomen in erect posture showed multiple air-fluid levels. Decision of exploratory laparotomy was taken. On laparotomy small intestine was found distended upto about 2 feet from ileocaecal junction. Rest of the small intestine and whole of the large gut was collapsed. At the junction of distended and collapsed small intestine, a band was present. On carefull dissection it was found that this band was a mesodiverticular band associated with meckel's diverticulum. The band was divided and meckels diverticulum arising from antimesenteric border of small gut was identified. Segmental resection of the meckels diverticulum containing intestinal segment followed by end to end anastomosis was done. After putting a drain abdomen was closed.

Postoperative recovery of the patient was uneventful and patient was discharged on $8^{\text {th }}$ postoperative day.
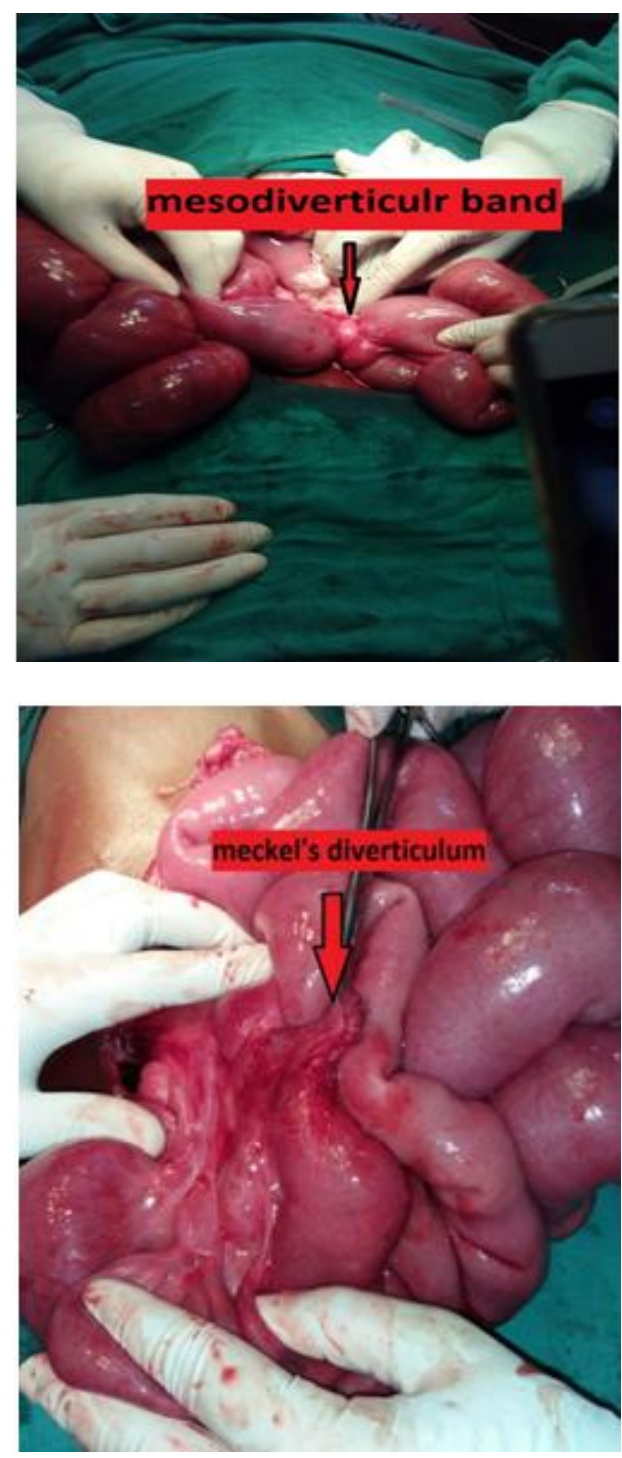


\section{Discussion}

The mesodiverticular band is formed when involution of vitelline arterial circulation of meckels diverticulum is incomplete or absent resulting in formation of a band. This mesodiverticular band may cause internal herniation of intestinal loops followed by instinal obstruction ${ }^{6}$. On emergency exploration of such cases transaction of mesodiverticular band followed by wedge resection or segmental resection of small bowel segment containingthe diverticulum followed by anastomosis is safe and effective treatment option.

\section{References}

[1] Haber JJ. Meckel's diverticulum. Am J Surg 1947; 73:468-485.

[2] Harkins HN. Intussusception due to invaginated Meckel's diverticulum. Ann Surg 1933; 98:1070-1095.

[3] S. Sameer Mohiuddin, DO, Adolfo Gonzalez, DO, Cynthia Corpron, MD. Meckel's Diverticulum with Small Bowel Obstruction Presenting as Appendicitis in a Pediatric Patient. JSLS (2011)15:558-561

[4] Vork JC, Kristensen IB. Meckel's diverticulum and intestinal obstruction- report of a fatal case. Forensic Sci Int. 2003; 138: 114-1145.

[5] Yoo JH, Cerqueira DS, Rodrigues AJ Jr., Nakagawa RM, Rodrigues CJ. Unusual case of small bowel obstruction: persistence of vitelline artery remnant. Clin Anat. 2003;16:173-175.

[6] Johnson GF, Verhagen AD. Mesodiverticular band. Radiology $977 ; 6: 409-12$.

[7] R.S.Williams. Management of meckel's diverticulum. Br.J.Surg. 1981;68: 477-480

[8] Joseph J. Cullen, Keith A. Kelly, Christopher R. Moir. Surgical Management of Meckel's

[9] Diverticulum -An Epidemiologic, Population-Based Study. Ann surg. 1994; 220:564-569

[10] DeBartolo HMJ, van Heerden JA. Meckel's diverticulum. Ann Surg 1976; 183:30-33.

[11] Weinstein EC. Meckel's diverticulum. J Am Geriatr Soc 1965; 13:903-907. 